\title{
Pre-Service Teachers' Experiences in Learning Robotics Design and Programming
}

\author{
Sevda KUCUK*, Burak SISMAN \\ Department of Computer Education \& Instructional Technology \\ Hasan Ali Yucel Education Faculty, Istanbul University-Cerrahpasa, 34452 Istanbul, Turkey \\ e-mail:sevda.kucuk@istanbul.edu.tr,burak@istanbul.edu.tr
}

Received: April 2018

\begin{abstract}
The aim of this study was to reveal pre-service teachers' experiences in learning robotics design and programming. Data were collected from 15 pre-service teachers through semi-structured interviews and analyzed using the content analysis method. Three themes were identified in this study: Course process, professional development and teaching children. The pre-service teachers indicated that they found opportunities to learn by doing and experience, enjoyed doing robotics activities and felt in flow in this process. They also expressed that the robotics programming course positively influenced their attitudes towards programming and improved their programming skills. They emphasized the importance of keeping their intrinsic motivation high by maintaining their individual efforts to solve problems. Moreover, they made various suggestions for teaching robotics to children. Implications are discussed in terms of practices for educational robotics in teacher training, and further research directions.
\end{abstract}

Keywords: educational robotics, pre-service teachers, teacher education, teaching robotics.

\section{Introduction}

Instructional technologies provide opportunities to transform education into something effective, productive and engaging, and are closely related to technological developments. Consequently, educational researchers carry out studies on how to integrate technological innovations of different fields into educational environments based on appropriate pedagogical approaches. In recent years, how to teach students knowledge and skills in a holistic way in Science, Technology, Mathematics and Engineering (STEM) has been one of the issues pointed out by many researchers. Various applications have been designed in educational environments from elementary school to university. One of the outstanding applications among them is educational robotics. In educational robotics, programmable robots are designed using plastic parts that can be assembled together.

\footnotetext{
* Corresponding author
} 
Students can learn about STEM subjects and skills when practicing with such applications (Barak and Zadok, 2009; Hussain, Lindh and Shukur, 2006; Martinez Ortiz, 2011). In addition, a fun and constructive learning environment is created as students take active roles by designing and programming robots (Alimisis, 2013; Bruciati, 2004).

Main theories behind educational robotics applications are constructivism and constructionism. The studies of Piaget and Papert are considered as a milestone in educational robotics. According to them, students are active builders in the learning process and learn best when they actively design and build products that are meaningful to them. The context in the knowledge of construction is very important. Students construct their knowledge as they deliberatively engage in building a public entity such as a sand castle on the beach or a technological artifact. Piaget (1974) states that the construction of knowledge in mind requires learners to work hands-on. Knowledge is constructed for the first time or existing knowledge is modified depending on experience. In the learning process, actively getting involved in practice and reasoning helps to acquire concepts and principles that lead to understanding (Ackermann, 2001; Alimisis, 2013; Harel, 1991; Ucgul, 2013). Context is also important in the construction of knowledge (Papert, 1980). Knowledge construction takes place as learners intentionally focus their attention on a common contextual object. Papert (1980) argues that an educational system that puts technology in the center provides students with the ability to cope with difficulties they may encounter in the learning process. So, to help students learn, technological opportunities should be offered to them. Papert (1980) conducted some of the earliest studies on Logo in educational contexts. Since then, studies on educational robotics have been a common subject of discussion (Benitti, 2012; Nugent, Bradley, Grandgenett, and Adamchuk, 2010; Somyurek, 2015). The use of robotics facilitates learning, especially when it focuses on learning through design-centered activities as it encourages children to interact with their environment and deal with realistic challenges (Alimisis, 2013; Somyurek, 2015). Children behave like designers and constructors when programming robots. They rely on their experiences to engage in activities of exploration and production as well as problem-solving (Goh and Ali, 2014). Children create robots using small robot parts. They may use pre-programmed software or write their own codes on computers to make robots functional. On that account, Papert said that "Given a good programming language, I see children struggling to make a program work in a way that they seldom sweat at their paper-and-pencil mathematics" (Papert, 1999, p. 4). Designing robotics activities for children is thus of great importance to enhance their STEM skills, especially for children of elementary school age. Therefore, it is advisable to plan and carry out such activities from preschool up to university education.

Students can actively learn by designing and creating three-dimensional and functional objects through such activities. In addition, by learning programming languages, students can program their own robots and get instant results. Various modular training sets (LEGO Mindstorms, Robotis Dream, VEX IQ, etc.) have been created so that educational robotics activities can be easily used in educational environments. Students design mechanical structures of robots by combining plastic parts contained in these sets. They create electronic components of robots by using supplied microprocessors and sensors, and they program robots by using block-based visual programming or text- 
based programming tools that are unique to these educational sets. During the programming process, students enable robots to interact with the environment by using various sensors sensitive to light, touch, sound and similar events. Thus, they can also develop various original educational robotics projects that can fulfill different functions in the direction of the goals they determine. In this process, students gain robotics design and programming skills by taking an active role at every stage of learning. Indeed, studies have shown that educational robotics activities can be effective in improving students' skills in problem solving, critical thinking, creative thinking, decision making, team work, and scientific process (Eguchi, 2014; Gerecke and Wagner, 2007; Lin et al., 2009; Mauch, 2001).

Especially in recent years, robotics activities in education have been rapidly expanding in educational environments all over the world. These activities not only improve the skills mentioned but also enable students to develop their skills in STEM fields by creating an active learning environment. Many educational institutions from elementary school to university have started to work in this area by providing their students with various robotics training kits. However, it is very important that the learning process with robots is designed to enhance STEM skills as well as the acquisition of this technology. To that end, the learning process needs to be organized according to appropriate pedagogical approaches. In educational robotics activities, cyclical approaches are used to develop students' creativity, problem solving and similar skills. The "Creative Thinking Spiral Instructional Model" developed by Resnick (2007) suggests a spiral cycle that includes the following steps: Imagining, designing, playing, sharing and reflecting. Another model, the Engineering Design Process, involves the stages of asking, imagining, planning, creating, developing and sharing (Rogers and Portsmore, 2004). Such approaches should allow students to develop experiences in building and designing artifacts. By using these approaches, enabling students to gain objectives systematically and purposefully will make it easier to manage the learning process and reach targeted outcomes.

In our country, Turkey, especially private schools have started to offer educational robotics activities in Information Technology classes or in club activities, using various educational robotics kits. Teachers, as the pioneers of change, have a significant role in creating effective and efficient settings for learning robotics. Literature shows that various training programs (Arlegui, Pina and Moro, 2013; Kay, Moss, Engelman and McKlin, 2014; Kim et al., 2015; Perritt, 2010) have been organized for teachers to learn robotics science to fill the gap for qualified teachers. There are various in-service training programs for teachers in our country as well, directed by the Ministry of National Education (MONE) as well as by private institutions. Nevertheless, more emphasis should be placed to training teachers in parallel with the rapid advancement of educational robotics technology (Kim et al., 2015; Pittí, Curto, Moreno and Rodríguez, 2013).

It is also important for pre-service teachers to be able to take such training during their undergraduate education. Such training programs support the professional development of pre-service teachers. As a matter of fact, robotics courses are becoming widespread in teacher training institutions around the world (Bruder and Wedeward, 2003; Hadjiachilleos, Avraamidou and Papastavrou, 2013; Kay et al., 2014; Kaya, Newley, Deniz, 
Yesilyurt and Newley, 2017; Kim et al., 2015; Majherová and Králík, 2017; Sullivan and Moriarty, 2009). In these courses, designing and programming robotics are taught to pre-service teachers. These courses address how to integrate robotics into educational environments as well as the pedagogical approaches by which robotics can be integrated into education. Studies have shown that learning robotics motivates pre-service teachers to do scientific research (Hadjiachilleos et al., 2013), enhances their self-confidence in how to learn and teach programming languages (Jaipal-Jamani and Angeli, 2017; Kay et al., 2014), and affects their pedagogical beliefs towards robotics education positively (Sullivan and Moriarty, 2009). Such training programs also enhance their engagement in STEM (Kim et al., 2015). However, there is limited effort to thoroughly reveal the learning experiences of pre-service teachers. It is important to know pre-service teachers' views and experiences in terms of robotics, considering the likelihood that if they are trained in this subject for a sufficient amount of time, they might take an important step towards professionalization in the field of educational robotics. Experiences of pre-service teachers can be a guide for educators and researchers in organizing such trainings. It is also thought that this study will contribute to the literature in terms of conducting studies on educational robotics effectively.

\section{Method}

This study was carried out as a case study, one of qualitative research methods, to reveal the experiences of pre-service teachers on learning robotics design and programming. In case studies, a certain case is examined with a holistic and in-depth perspective, and themes related to the case are revealed (Creswell, 2014; Yin, 2009). In this study, the case study method was used in order to deeply understand the experiences of pre-service teachers.

\subsection{Participants}

The participants of the study consisted of 15 pre-service teachers ( 9 females and 6 males, aged 19-22 years) from different departments taking the course of Robotics in Education. The course was offered as an elective course at a major university in Turkey. All of the pre-service teachers who took this course participated in the study voluntarily. The participants of the study were university students -9 from the department of Computer Education and Instructional Technology (CEIT), 2 from the department of Talented Education, 2 from the department of Elementary Education and 2 from the department of Science Education. The participants stated that they did not have experience in robotics design before taking the course. With regard to their programming experiences, the pre-service teachers who were studying in the CEIT department had basic level of knowledge in various programming languages, although not in robotics programming. The pre-service teachers in the other departments learned programming for the first time in this course. For this reason, in the programming section of the course, activities to 
develop algorithmic thinking skills were emphasized, considering the differences in the preliminary knowledge levels of the participants. The pre-service teachers participated in the course activities in groups of three to four and thus practiced peer learning.

\subsection{Study Process}

The course was four hours a week. It lasted a total of 13 weeks during the fall 2017 semester. Course activities were carried out using the Robotis Dream educational robotics kit. The Robotis Dream educational robotics kit consists of four levels. In the first level, there are activities starting with the introduction and assembly of parts and continuing with the creation of robots using motors as well as the mechanisms of motion. In the second level, there are activities to design robots that can detect events and objects in their environments using their sensors and decide on actions using their micro-controllers. There are also activities to create algorithms. In the third and fourth levels, a programming instruction is given, and more advanced robots are created. This training kit includes batteries, geared motors, servo motors, various sensors, LEDs, colored plastic sheets, plastic screws, Bluetooth modules, cables, a key and a remote control. The training kit has a text-based programming interface based on the $\mathrm{C}$ programming language. Within the scope of this course, different activities from all four levels were selected and carried out. Some of the robotics activities that were carried out during the course are given in Fig. 1. An exemplary scene from the programming screen is shown in Fig. 2.

The lessons were conducted in the robotics laboratory. Each group was given an educational kit, and the participants collaborated in groups. At the beginning of the course, the instructor gave introductory information (such as the working principles of sensors and motion mechanisms) to carry out robotics activities. The groups designed robots by following the steps in the instructional manual included in the educational set. While the robots were designed collaboratively in groups, pre-service teachers individually wrote program codes based on the determined algorithm for the robots. When they had difficulties, the instructor guided the participants. In the first weeks of the course, the participants practiced activities for designing robots. Afterwards, they did activities for both designing and programming the robots. Later on, various pedagogical approaches were utilized to help the pre-service teachers gain knowledge and experience on strategies for teaching robotics to children. The process of
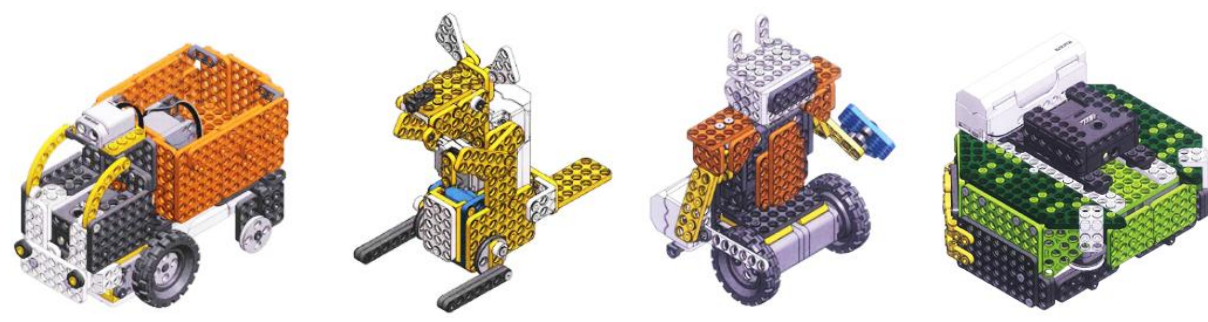

Fig. 1. Some robotics activities that were carried out during the course. 


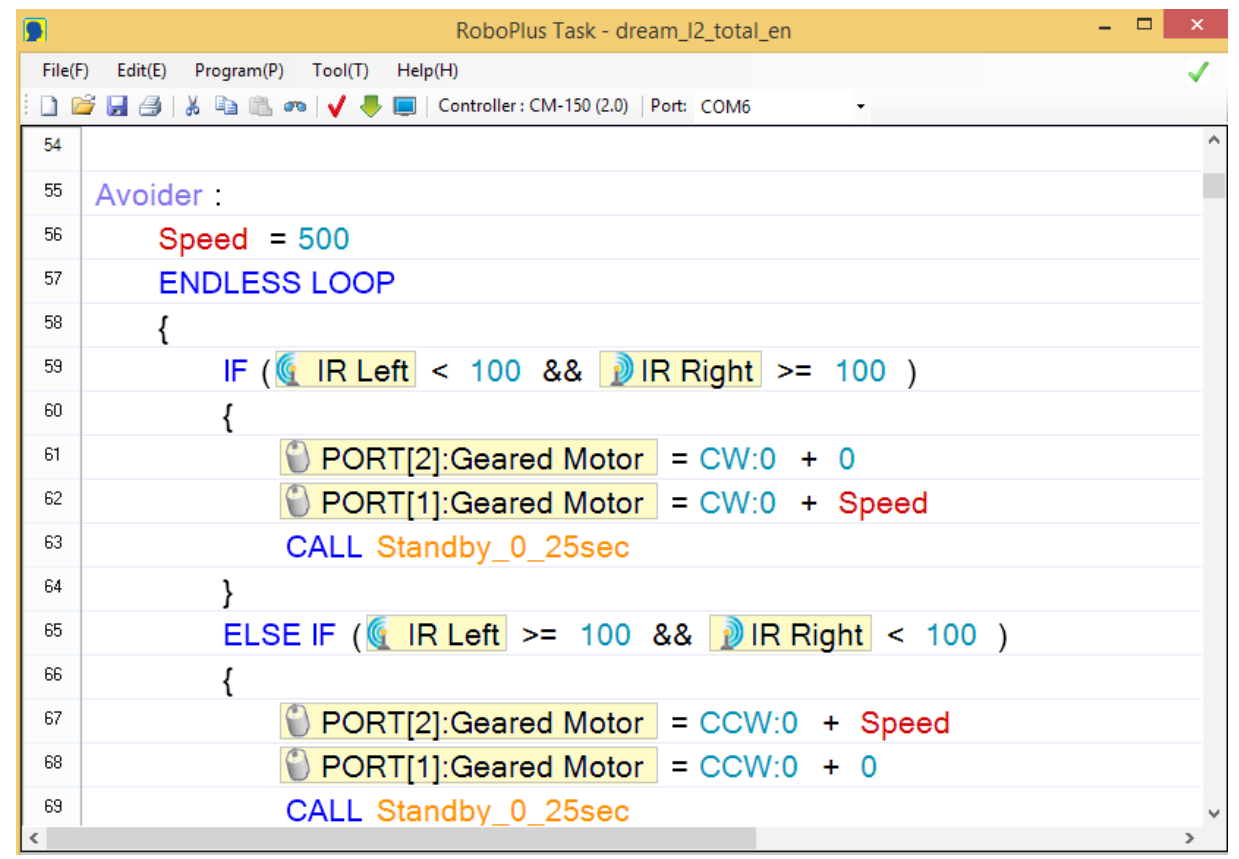

Fig. 2. An exemplary image from the programming interface.

teaching robotics was linked to the Creative Thinking Spiral Instructional Model and the Engineering Design Process throughout the course, and examples in line with the models were presented. In addition, discussions were held on how to use gamification and storifying strategies to attract children's attention. Each group prepared robotics activities of their choice within the framework of a certain pedagogical approach as a lesson plan by using gamification and storifying strategies. The groups, then, presented them during the lessons. In-class discussions were held to make a critique of each group's presentation. Thus, it was tried to help pre-service teachers master the pedagogy of robotics.

In the last week of the course, the groups were asked to create their own original robot designs as a final project and to define tasks in a story concept of their own choice. They programmed the robots by following the design steps and algorithms to accomplish the tasks they had defined. The pre-service teachers were also encouraged to create a lesson plan that had stories - with real-life scenarios or with scenarios that could improve the creativity of their own students - in their projects. This is because they would guide elementary and middle school students in building such robots in the future. The groups presented their functional robots and instructional scenarios. Some of the robots developed by the groups are given in Fig. 3. Some groups ensured that the robots could be used by children in a classroom environment. A demonstration of this is given in Fig. 4. 

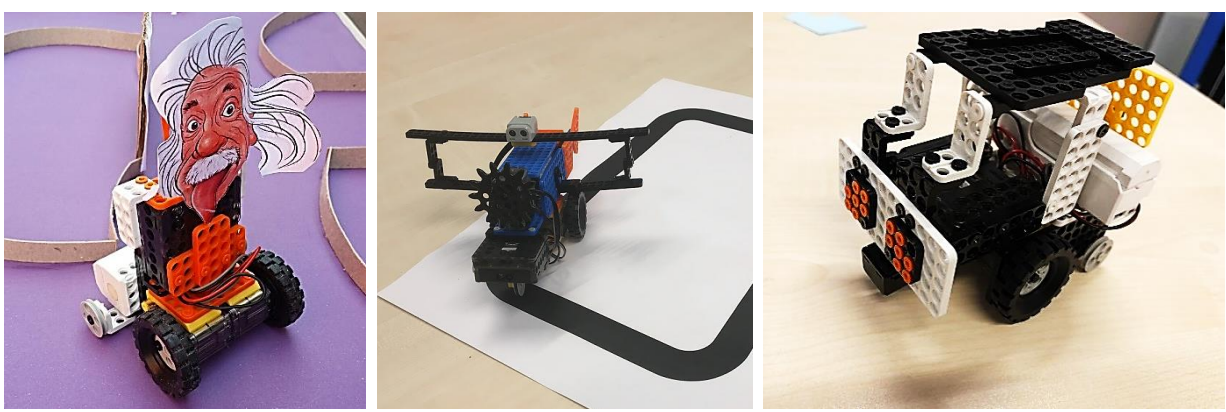

Fig. 3. Scenes from group projects.
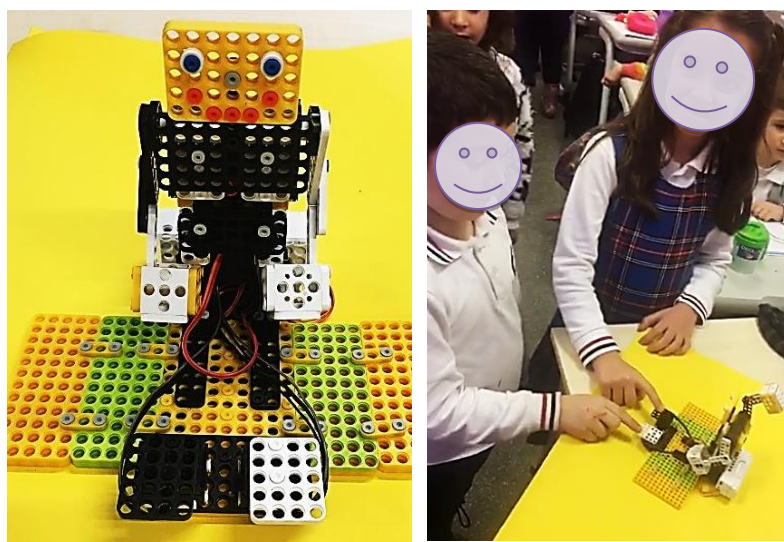

Fig. 4. Testing the "knowledge contest" robot in a classroom environment.

\subsection{Data Collection Instrument and Data Analysis}

An interview form consisting of 15 questions about the process of learning robotics design and programming was used as the data collection instrument. The interview form was developed by the researchers based on the relevant literature. Two subject matter experts checked the interview questions in terms of clarity and content validity. Moreover, a pilot interview was conducted with a pre-service teacher who took the same course in the preceding semester. The necessary modifications were made, and the interview form was finalized. In the interview form, questions such as the following took place: "Have you been having difficulties in doing the robotics activities during the course? What difficulties have you encountered? What have you done when you encountered difficulties? How have you got over the difficulties? How have you felt cognitively and emotionally while working on the robotics programming activities? How would you like to use what you have learned in this course, in your future as a teacher? Could you please explain with examples? How would you associate what you have learned with your own field of study?" The semi-structured interviews were carried out with par- 
ticipants in the last week of the semester. All participants voluntarily participated in the study. The interviews were recorded using an audio recorder and were transcribed by the researchers. The data were analyzed using Nvivo 11.0 software by using content analysis and descriptive analysis methods. When the researchers analyzed the interviews, they worked together to decide on the themes, categories and codes, through exchange of ideas. The themes, categories and codes that emerged from the interviews were visualized and presented in the findings section. In addition, the views of the participants for each theme were also directly quoted. The participants were labeled with pseudo names according to their departments. The pre-service teachers from the CEIT department were coded as $\mathrm{C} 1, \mathrm{C} 2, \ldots, \mathrm{C} 9$, those from the Talented Education as $\mathrm{T} 1$ and $\mathrm{T} 2$, those from the Elementary Education as E1 and E2, and those from the Science Education as S1 and S2. In order to improve the reliability of the study, the themes, categories and codes revealed by the researchers were checked by another expert, ensuring the intercoder reliability.

\section{Findings}

As a result of the content analysis of the interviews, 3 themes were identified: "Course Process", "Professional Development" and "Teaching Children". The codes and categories for each theme are presented below, under headings, using drawings, with direct quotes from the participants. Each participant's pseudo name is given alongside their statements. The themes emerging in the study are given in Fig. 5.

The "course process" theme refers to what the pre-service teachers experienced when doing the activities during the course. The "professional development" theme refers to what the pre-service teachers thought in terms of the possible contribution of educational robotics to their careers. Lastly, the "teaching children" theme presents what the pre-service teachers suggested in terms of teaching robotics to children, based on the pedagogical and technical experiences they gained from the course.

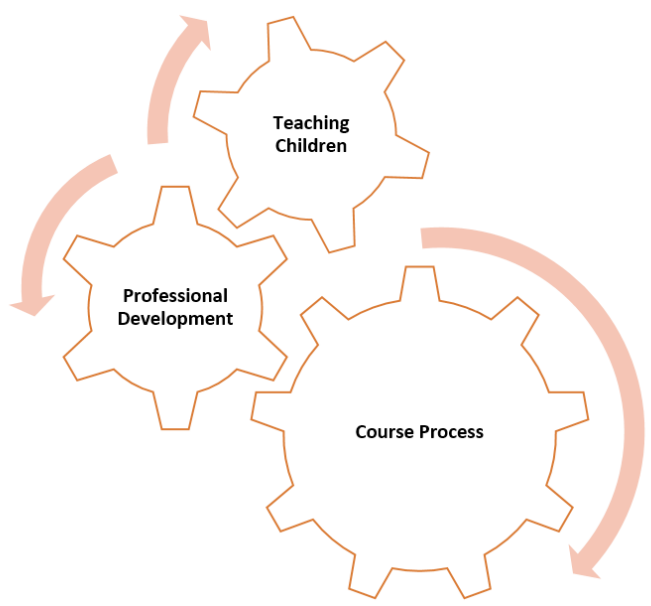

Fig. 5. The themes based on interview results. 


\subsection{The Course Process}

As a result of the content analysis of the interviews, the following categories were obtained under the course process theme: Learning process, difficulties encountered, problem solving methods and project development process. The codes under each category are presented in Fig. 6. These categories represent the outstanding dimensions of the educational robotics course. The learning process category reflects the pre-service teachers' learning experiences comprehensively. Moreover, the nature of educational robotics activities involves some complex situations during robotics design and programming, solving these problems, and developing a project. Therefore, the other three categories were revealed.

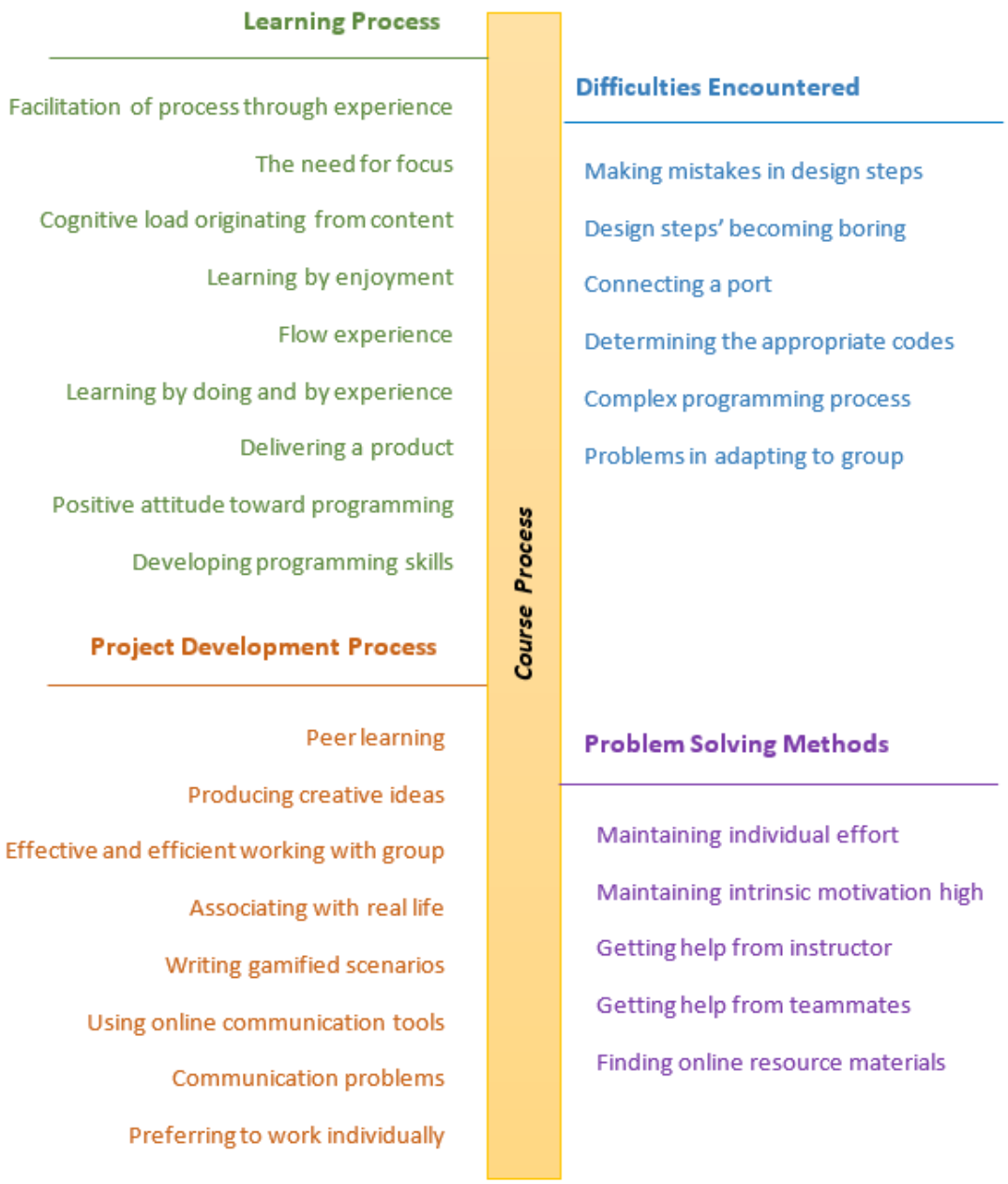

Fig. 6. "Course process" theme. 


\subsubsection{Learning Process}

The participants noted that as they gained experience, it got easier to learn robotics design and programming. They also stated that it was important to focus on the process of learning. They claimed that the content of the course caused cognitive load. Nevertheless, they enjoyed learning and became wholly absorbed in the flow. The robotics learning was satisfactory because it was based on learning by doing and by experience. They were also satisfied that they delivered a complete product after all. They stated that the robotics programming course positively influenced their attitudes towards programming and improved their programming skills. Some of the statements of the participants are given below.

"Whether it is the stage of producing a robot or the stage of coding that you are in, your mind is always on the run. There are many factors that you need to care for, so after a while you mentally get tired." C1

"When I was working on the robotics programming activities, I was feeling good because I started/continued to learn something. There were times when programming was boring to me during some difficult times, but I had fun in general, and after programming, I was totally immersed in trying the codes on the robot." T1

"When I started to program, I wanted to see the result of the program by experimenting. The robotics course seems to have been prepared just for this. You see your mistakes, you modify and try again, and when it works, it gets to be your success. " C2

"I had prejudices, but those judgments have now been cleared. However, because I came to the course without knowing anything and the course was not taught from scratch, I have struggled at certain points. Right now, I do not see my level to be sufficient. I can improve the things that I can do based on support. I do not think there are things I cannot achieve or that I cannot learn. I think I can improve myself." SI

\subsubsection{Project Development Process}

The participants designed their own robots as a final project by working with their teammates at the end of the course. They stated that peer learning took place during this stage. They also stated that working with the group was effective and productive, so they were able to produce creative ideas. Moreover, the participants stated that they paid attention to relate their projects to real life. They designed gamified scenarios to teach the robotics to children. During the project development stage, they frequently communicated with each other through online communication tools. Some of the statements of the participants are given below.

"In the process of the project, we did everything together and decided together. At each step, we were in touch. First, we brought forward an 
idea, developed it and modified it. We modified it while we were doing it as well." C3

"As elementary school teachers, we said that we could teach kids something anyhow. So, we thought about the traffic rules. We used a car, so that it would be something children would love and learn the most important traffic rules." $E 1$

"I think working with the group is effective in coming up with creative ideas. He could bring forth ideas that did not come to my mind. I could bring forth ideas, too. We were completing each other with my teammates." T2

Some participants stated that there were communication problems among group members and that they preferred to work individually. One of the statements of the participants is given below.

"My personal opinion is that when I work individually, I get a better product compared to group work. Even if there is a division of labor in groups, the program can get hindered if someone does not do his job sufficiently. And, this can ruin the group's morale. In fact, one person's task gets left to the other members of the group." $\mathrm{C} 4$

\subsubsection{Difficulties Encountered}

The participants stated that they faced two major types of difficulties during the course: mistakes they made in the design steps and problems they experienced in connecting ports. Some of the participants also thought that the design steps were boring, and this was a difficulty. Determining appropriate program codes during the programming process and the complexity of the programming process were the other, less-mentioned difficulties. Moreover, problems in adapting to groups made the learning process difficult. Some of the statements of the participants are given below.

"Some robots are giving us quite a hard time. I contemplate that 'let's do it quickly, get it done and hope it works.' When we hurry it, things are backfiring for good and all." C2

"I was getting confused especially about the DC motors in the programming section and in the "if," "else if," and "else" parts. Those parts were tiring me mentally." T2

"Failing to think about the finest details when programming could cause some malfunctions in the process. Obviously, this can be a little tiring. "S1

“Redoing some steps after making mistakes in robotics design ..." C9 
"It was a problem to forget what we plugged into which port." C5

"Sometimes there may be disagreements within the group." C6

\subsubsection{Problem Solving Methods}

The participants indicated that they overcame the problems that they encountered by maintaining their individual efforts and keeping their internal motivation high in the process of robotics design and programming. They also stated that they requested help from their group members and course instructor when needed. Some participants also pointed out that they were trying to solve the problems they faced using online resources. Some of the statements of the participants are given below.

“I got support from my teammates at times when I had difficulties.” E2

"I think that at the moment you realize you made a mistake in the robot's construction stages, the most important thing is to maintain the motivation that you had at the beginning." T1

"I was watching programming videos on the Internet ..." E1

\subsection{Professional Development}

Another theme that emerged as a result of the content analysis of the interviews was professional development. This theme represents what the pre-service teachers thought in terms of the possible contribution of educational robotics to their careers. The codes included in this theme are given in Fig. 7. The participants noted that receiving training in robotics design and programming was important in terms of adapting to new technology trends and that they understood the pedagogy of robotics through the training they received. In addition, the participants stated that the training they received allowed them to think about professionalizing in the field of robotics and that they focused on how they could integrate robotics into their own fields. They also stated that teachers should have knowledge about robotics and recommended such lessons to other pre-service teachers. Some of the statements of the participants are given below.

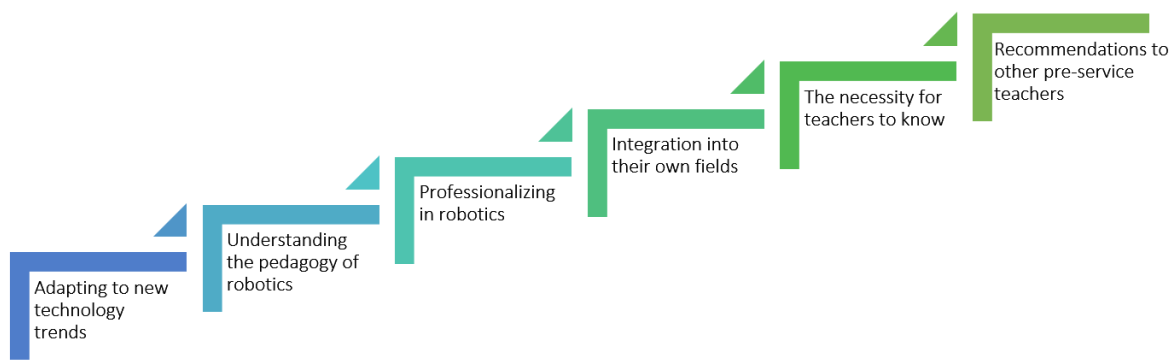

Fig. 7. "Professional development" theme. 
"In the age of technology, it was absolutely helpful to get innovative, new information." E2

"Before I started this course, I thought robotics was a difficult and insurmountable area in certain ways. My current thoughts have completely changed. Now, I think I can improve my skills, and I see myself at a better place in robotics programming. I want to give programming education to many children who are interested in robotics in the future." T1

"I think it is necessary to make the process systematic with the steps of a certain method, because this makes it easier for the teacher to teach and for the course to work. It helps students comprehend the subject easily. The studies I have done for this purpose have been helpful to me, because the robotics education gave me an idea of how I would be organized during the course." T2

"We live in the age of technology, and children are also intertwined with technology. Teachers also play a role here in directing them, so teachers need to learn about such technologies. " S2

"I try to put into practice what I learned in this course with, for example, gifted and talented children who I believe to have interest in robotics." $T 1$

"I would recommend it to friends in my own field of study. I think it is a good advantage to know this course as a teacher, because I think it would be very useful to support the lesson with robotics." S1

\subsection{Teaching Children}

This theme presents what the pre-service teachers suggested in terms of teaching robotics to children, based on the pedagogical and technical experiences they gained from the course (Fig. 8). The participants stated that today's children had interest and curiosity in robotics, which enhanced their learning motivation. They said that the learning process was easier in the robotics programming phase if children knew English. The following were emphasized as requirements when teaching robotics to children: (1) it is possible to have children collaborate in the process of robotics design, (2) attention must be paid to ensure that motors are connected to correct ports in order to minimize mistakes in the design phase, (3) programming should be taught first, and thus the concept of programming should be understood well by children, and (4) in robotics programming, children should be given opportunities to study individually and to learn by trial and error. The participants talked about the importance of associating instruction with real life and going through concrete problems when teaching robotics. They mentioned that, during the teaching process, children should be asked questions that would attract their attention 

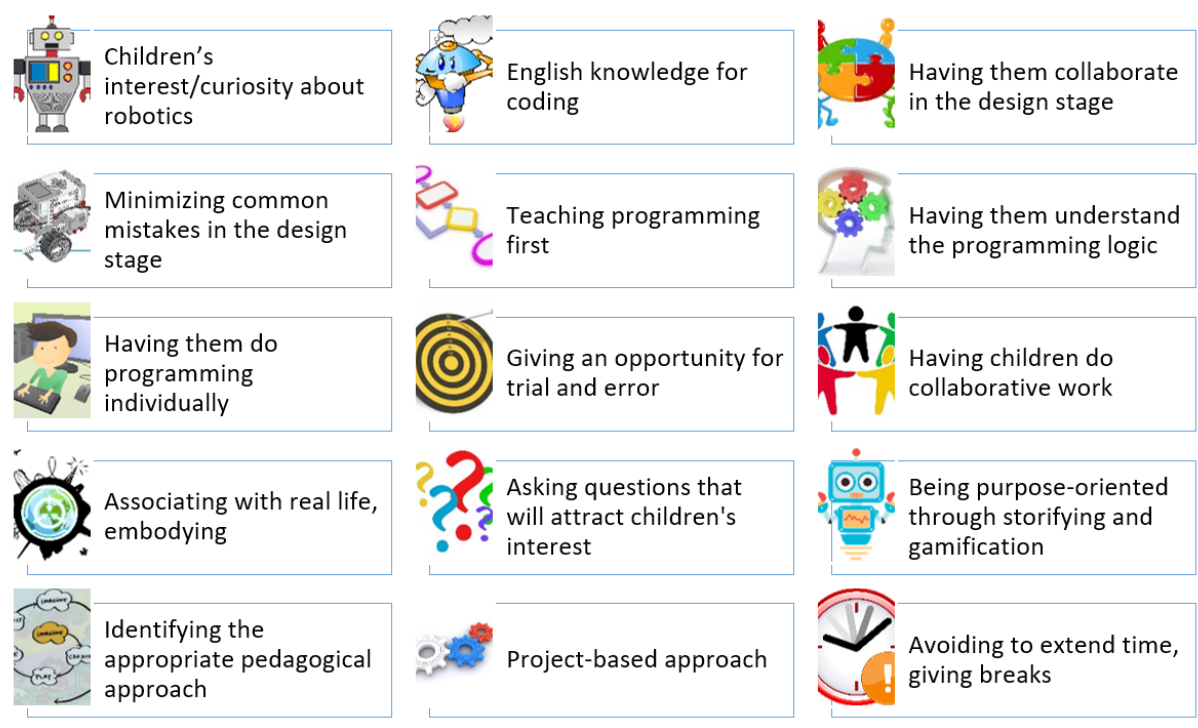

Minimizing common

mistakes in the design

stage

Having them do

programming

trial and error

Having children do collaborative work

Having them understand the programming logic

Fig. 8. "Teaching children" theme.

and encourage them to think. They also mentioned that it was important to achieve a certain goal by using storifying and gamification strategies. In addition, they emphasized that appropriate pedagogical approaches should be applied in the instructional process, such as the Creative Thinking Spiral Instructional Model and the Engineering Design Process. A project-based approach would also be a suitable approach. Some participants suggested that students should be given breaks when necessary in order to use the time better. Some of the statements of the participants are given below.

"In order to learn robotics programming, it is necessary to take a programming course beforehand. Children will not have difficulty in robotics programming if the basics of programming are taught well. " C7

"Every child has to program on their own. It is necessary to find out if they understand or not. If it is realized that they have not learned, then it is necessary to make an effort to have the child understand the topic." E1

"Children should be allowed to try and make mistakes, so they can see their mistakes." C1

"I think that robotics training by gamification will draw attention of children more and motivate them to learn." C6

"I think it is important to address the imaginary world of children by paying attention to their age group. These features must be considered. I think it will be effective if they are given time to study individu- 
ally to design the robot of their dreams, in order to highlight their interests and skills." S1

"I believe that the Creative Thinking Spiral Instructional Model will be very useful in robotics education, because I think this instructional model addresses many developmental areas of children." T2

"It should be preferred to embody programming codes mainly by using real life examples. Because, children understand it better by thinking more tangibly, not intangibly. And, since it is from life, it enhances the persistence of knowledge." C7

"Children are having a hard time, because they are unable to understand the words in English. I think they would not have difficulty if they knew the Turkish equivalents of the words or if the program was in Turkish." C3

\section{Discussion and Conclusion}

This study aimed to reveal the experiences of pre-service teachers about the process of learning robot design and programming. Three themes emerged based on the results: "course process", "professional development" and "teaching children." The following sub-themes emerged as part of the course process theme: Learning process, project development process, difficulties, and problem-solving methods. It was found that the learning process required concentration and that course content could create a cognitive load. Nevertheless, despite the difficulties experienced at the beginning, the process became easier as the participants gained experience. Indeed, in general, because the design stage of educational robotics activities is based on hands-on activities, the acquisition of these skills takes time. However, the programming stage may also have been difficult for students who did not have programming skills at the beginning. The participant views were also in this direction. The programming stage of educational robotics activities can be particularly complicated. For this reason, it is possible that the intrinsic cognitive load of participants increases in educational robotics activities (Bruciati, 2004). As a matter of fact, complex situations lead to the formation of intrinsic cognitive load (Clark, Nguyen and Sweller, 2006; Paas, Renkl and Sweller, 2003). On the other hand, the participants indicated that during the process, they found opportunities to learn by doing and by experience, they had fun, and they felt in flow when performing robotics activities. Concordantly, it is also stated in the literature that educational robotics activities are a fun and effective way to come up with constructive learning environments (Alimisis et al., 2010; Goh and Ali, 2014; Lin et al., 2009). Moreover, the participants expressed their satisfaction with being able to produce an artifact in the end. In addition to that, they stated that robotics programming course positively influenced their attitudes towards programming and improved their programming skills. Parallel results have also been obtained in the literature (Jaipal-Jamani and Angeli, 2017; Kay et al., 2014; Majherová and 
Králík, 2017). It was found that working with a group in the process of developing final projects was effective and productive, allowed to generate creative and real life related ideas and supported peer learning. Such benefits of working with groups in educational robotics activities come to the forefront in the literature, as well (Atmatzidou and Demetriadis, 2012; Camilleri, 2017; Liu, Lin and Chang, 2010). However, some participants stated that they sometimes had communication problems with members of their groups. One participant preferred to work individually. Preference towards individual work may be due to characteristics of participants (Lai, 2011).

The participants indicated that the difficulties they encountered during the process included making mistakes in the design process, getting bored due to the elongation of design process, being unable to connect ports correctly, being unable to determine appropriate codes for targeted outcomes, and the fact that some robots involved complex programing. Mistakes made in the design process of educational robotics activities usually originated from the fact that the participants connected the boards to wrong ports since they did not carefully examine the guidelines in the instructional manual and they connected the motors to wrong ports. The participants wanted to complete designing their robots as soon as possible and move on to the programming stage. This may have caused them to act hastily and make mistakes. The difficulties they encountered in the programming process may be due to the fact that they did not initially write algorithms well and did not understand the function of each code well. However, as the participants themselves pointed out, as they gained experience, they began to overcome difficulties. In addition to that, the participants emphasized the importance of keeping intrinsic motivation high by maintaining their individual efforts to solve problems. They also pointed out that they were receiving help from their group members and course instructor from time to time and were trying to find online instructional materials. Collaborative studies in educational robotics activities enable faster resolution of problems (Liu et al., 2010; Mitnik, Nussbaum and Recabarren, 2009).

The participants emphasized that this course was offered to support their professional development. With the help of this course, they adapted to new technology trends, thought about professionalizing in the field of robotics, understood the pedagogy of robotics, and paid attention to integrating robotics pedagogy into their fields of study. They also stated that teachers should have knowledge about robotics. They recommended such courses to other pre-service teachers based on their interests. As a matter of fact, teachers have shown interest in robotics training in order to improve their professional skills as stated in the literature (Bruder and Wedeward, 2003; Hadjiachilleos et al., 2013; Kay et al., 2014; Kim et al., 2015; Sullivan and Moriarty, 2009).

Finally, the participants made various recommendations for teaching robotics to children, based on the knowledge, skills and experience that they gained in robotics technology and in the pedagogy of this technology (Fig. 8). It is very important that these recommendations are based on the experiences they acquired from the learning process. Educational robotics activities have been drawing attention with certain benefits such as improving children's imagination, providing a game/entertainment environment, enabling them to develop their own products, developing STEM skills, and providing contextual thinking (Liu, Lin, Feng and Hou, 2013; Lin et al., 2009; Gerecke and Wagner, 
2007). It is very important that the educational environment is designed effectively to achieve such gains. These suggestions may be useful in creating effective and efficient learning environments for teaching robotics.

In conclusion, it was found that the course, which was offered to teach pre-service teachers the robotics design and programming skills, was effective in supporting their professional development. When learning robotics design and programming, the preservice teachers had fun, were carried away, and found opportunities to learn by doing and experience. However, it was found that the course content could cause a cognitive load from time to time and that the process of robotics design and programming required a good concentration. It was also revealed that project development was an important part of the learning process in educational robotics activities. In this process, the preservice teachers experienced some difficulties and developed various problem-solving methods to overcome these difficulties. However, as the study was a case study, the results have a limitation in terms of generalizability. The pre-service teachers developed educational scenarios for teaching robotics to elementary and middle school children. But, they could not find the chance to apply the lesson plans that they developed in a real classroom environment. For this reason, the pre-service teachers did not directly interact with children. In addition, the participants were from only four different departments. All these can be seen as limitations of the study. The following suggestions are presented in the light of the results obtained from this study.

Course Process: Those who do not have basic programming knowledge may have difficulty in learning robotics programming. Supplementary simple activities may be offered to pre-service teachers who are not experienced in programming. This process can be supported with educational videos. Pre-service teachers can make mistakes when designing robots. In such cases, many parts of robots may have to be disassembled to correct the mistakes. This was found to reduce the pre-service teachers' motivations. For this reason, extra practice activities can be designed to avoid frequently-made mistakes (port connections and joint connections) to minimize the design challenges. Teamwork accelerates the design process and allows learning from peers. However, some groups may experience communication problems. In such cases, participants can be given opportunities to work individually depending on their personal characteristics. Changes can be made in groups to prevent communication problems.

Professional Development: It is recommended to teachers and pre-service teachers to specialize in the field of robotics and integrate robotics into lessons in order to catch children's interest in their lessons. Educational robotics courses to be offered to teachers or pre-service teachers should be planned well in terms of duration and content. Long-term studies should be undertaken rather than short-term studies on small workshops. It is important especially for the pre-service teachers in CEIT departments to have computational thinking skills. They will be teaching programming to young children. They need these skills to be able to help their own students gain these skills. For this reason, such courses can be promoted in faculties of education in order to provide preservice teachers in CEIT departments with computational thinking and programming skills. Such courses can also help them develop positive attitudes towards programming. 
Long-term courses should be offered to teachers and pre-service teachers who want to teach children robotics and specialize in this area. In these courses, appropriate methods and approaches to understand the pedagogy of robotics should be emphasized. In such courses, it should be emphasized how pre-service teachers in departments other than the CEIT department and teachers can integrate robotics into their own fields. Original robotics activities can be designed by integrating them with the curriculum especially with the help of teachers and pre-service teachers in the science field.

Teaching Children: In order to create a collaborative working environment for building robots, classrooms should be organized to promote teamwork. This can enable learning from peers as well as developing social communication skills. In the programming stage of robots, every child should be allowed to program robots individually. In this way, the subjects of programming that are hard to understand can be identified, and measures can be taken to minimize problems. The robotics activities in lessons should involve scenarios and be linked to real life examples. They should be presented as solutions to concrete problems. In order to reinforce the subjects taught, students may be requested to design and program original robots by using a projectbased approach.

Future Studies: In this study, preservice teachers learned robotics design and programming, and their experiences in this learning process were revealed. It can be conducted a longitudinal study to examine how these pre-service teachers integrate the robotics technology into their future classes. In future studies, teachers' experiences in teaching robotics design and programming to children can be determined. Educational programs can be developed by collaborating with teachers working in fields other than CEIT, through robotics activities targeting their own fields. Comprehensive quantitative studies with larger sample groups can be conducted to investigate views of teachers in teaching robotics.

\section{Acknowledgement}

This study was supported by Scientific Research Project Coordination Unit of Istanbul University (Project Numbers: 52382, 43480)

\section{References}

Ackermann, E. (2001). Piaget's constructivism, Papert's constructionism: What's the difference. Future of Learning Group Publication, 5(3), 438.

Alimisis, D. (2013). Educational robotics: Open questions and new challenges. Themes in Science and Technology Education, 6(1), 63-71.

Alimisis, D., Arlegui, J., Fava, N., Frangou, S., Ionita, S., Menegatti, E., Monfalcon,S., Moro, M., Papanikolaou, K., Pina, A. (2010). Introducing robotics to teachers and schools: Experiences from the terecop project. Retrieved 5 May 2018, from http://hermes.di.uoa.gr/frangou/papers/eurologo\%202010.pdf

Arlegui, J., Pina, A., Moro, M. (2013). A PBL approach using virtual and real robots (with BYOB and LEGO 
NXT) to teaching learning key competences and standard curricula in primary level. In Proceedings of the First International Conference on Technological Ecosystem for Enhancing Multiculturality (pp.323-328). New York, NY, USA: ACM.

Atmatzidou, S., Demetriadis, S. (2012). Evaluating the role of collaboration scripts as group guiding tools in activities of educational robotics: Conclusions from three case studies. In 2012 IEEE 12th International Conference on Advanced Learning Technologies (pp. 298-302). IEEE.

Barak, M., Zadok, Y. (2009). Robotics projects and learning concepts in science, technology and problem solving. International Journal of Technology and Design Education, 19(3), 289-307.

Benitti, F. B. V. (2012). Exploring the educational potential of robotics in schools: A systematic review. Computers \& Education, 58(3), 978-988.

Bruciati, A.P. (2004). Robotics technologies for K-8 educators: A semiotic approach for instructional design. Education Faculty Publications. Paper 56. http://digitalcommons .sacredheart.edu/ced_fac/56

Bruder, S., Wedeward, K. (2003). Robotics in the classroom. IEEE Robotics \& Automation Magazine, 10(3), 25-29.

Camilleri, P. (2017). Minding the gap. Proposing a teacher learning-training framework for the integration of robotics in primary schools. Informatics in Education, 16(2).

Clark, R.C., Nguyen, F., Sweller, J. (2011). Efficiency in learning: Evidence-based guidelines to manage cognitive load. San Fransisco: Josey-Bass Inc. Publishers.

Creswell, J.W. (2014). Research design: Qualitative, quantitative, and mixed methods approaches (4nd ed.). Thousand Oaks, CA: Sage.

Eguchi, A. (2014). Educational robotics for promoting 21 st century skills. Journal of Automation Mobile Robotics and Intelligent Systems, 8(1), 5-11.

Gerecke, U., Wagner, B. (2007). The challenges and benefits of using robots in higher education. Intelligent Automation and Soft Computing, 13(1), 29-43.

Goh, H., Ali, M.B. (2014). Robotics as a tool to stem learning. International Journal for Innovation Education and Research, 2(10), 66-78.

Hadjiachilleos, S., Avraamidou, L., Papastavrou, S. (2013). The use of lego technologies in elementary teacher preparation. Journal of Science Education and Technology, 22(5), 614-629.

Harel, I. (1991). Children designers. Ablex pub. Corp. New Jersey: Ablex Publishing.

Hussain, S., Lindh, J., Shukur, G. (2006). The effect of LEGO training on pupils' school performance in mathematics, problem solving ability and attitude: Swedish data. Educational Technology Society, 9(3), $182-194$.

Jaipal-Jamani, K., Angeli, C. (2017). Effect of robotics on elementary preservice teachers' self-efficacy, science learning, and computational thinking. Journal of Science Education and Technology, 26(2), 175-192.

Kay, J.S., Moss, J.G., Engelman, S., McKlin, T. (2014). Sneaking in through the back door: Introducing K-12 teachers to robot programming. In Proceedings of the 45th ACM Technical Symposium on Computer Science Education (pp. 499-504). New York, NY, USA: ACM.

Kaya, E., Newley, A., Deniz, H., Yesilyurt, E., Newley, P. (2017). Introducing engineering design to a science teaching methods course through educational robotics and exploring changes in views of preservice elementary teachers. Journal of College Science Teaching, 47(2), 66-75.

Kim, C., Kim, D., Yuan, J., Hill RB., Doshi, P., Thai, CN. (2015). Robotics to promote elementary education pre-service teachers' STEM engagement, learning, and teaching. Computers \& Education, 91, 14-31.

Lai, E. (2011). Collaboration: A literature review. Upper Saddle River, NJ: Pearson. Retrieved 5 May 2018, from http://www . pearsonassessments.com/hai/images/tmrs/Collaboration-Review.pdf

Lin, C., Liu, E.Z., Kou, C., Virnes, M., Sutinen, E., Cheng, S-S. (2009). A case analysis of creative spiral instruction model and students' creative problem solving performance in a Lego ${ }^{\circledR}$ robotics course. In: Chang, M., Kuo, R., Kinshuk, Chen, G.-D., Hirose, M. (eds.) Edutainment 2009. LNCS, vol. 5670, pp. 501-505. Springer, Heidelberg.

Liu, E.Z.F., Lin, C.H., Chang, C.S. (2010). Student satisfaction and self-efficacy in a cooperative robotics course. Social Behavior and Personality: An International Journal, 38(8), 1135-1146.

Liu, E.Z-H., Lin, C-H., Feng, H-C., Hou, H-T. (2013). An analysis of teacher-student interaction patterns in a robotics course for kindergarten children: A pilot study. The Turkish Online Journal of Educational Technology, 12(1), 9-18.

Majherová, J., Králík, V. (2017). Innovative Methods in Teaching Programming for Future Informatics Teachers. European Journal of Contemporary Education, 6(3), 390-400.

Martinez Ortiz, A. (2011). Students learning rate and proportion using engineering LEGO robotics. In American Society for Engineering Education annual conference, Vancouver, British Columbia, Canada.

Mauch, E. (2001). Using technological innovation to improve the problem-solving skills of middle school stu- 
dents: Educators' experiences with the LEGO Mindstorms robotic invention system. The Clearing House, 74(4), 211-213.

Mitnik, R., Nussbaum, M., Recabarren, M. (2009). Developing Cognition with Collaborative Robotic Activities. Educational Technology \& Society, 12(4), 317-330.

Nugent, G., Bradley, B., Grandgenett, N., \& Adamchuk, V. I. (2010). Impact of robotics and geospatial technology interventions on youth STEM learning and attitudes. Journal of Research on Technology in Education, 42(4), 391-408.

Paas, F., Renkl, A., Sweller, J. (2003). Cognitive load theory and instructional design: Recent developments. Educational Psychologist, 38, 1-4.

Papert, S. (1980). Mindstorms: Children, computers and powerful ideas. New York: Basic Books.

Papert, S. (1999). Vision-making, new technologies, and powerful ideas in education. A talk at Heartland Area 11 Educational Agency/Drake University. Des Moines, IA: April 30, 1999.

Perritt, D.C. (2010). Including professional practice in professional development while improving middle school teaching in math. National Teacher Education Journal, 3(3), 73-76.

Piaget, J. (1974). To understand is to invent. N.Y.: Basic Books.

Pittí, K., Curto, B., Moreno, V., \& Rodríguez, M. J. (2013). Resources and features of robotics learning environments (RLEs) in Spain and Latin America. In Proceedings of the First International Conference on Technological Ecosystem for Enhancing Multiculturality (pp. 315-322). New York, NY, USA: ACM. http://doi.org/10.1145/2536536.2536584

Resnick, M. (2007). Sowing the seeds for a more creative society. Learning \& Leading with Technology, 35(4), $18-22$.

Rogers, C., Portsmore, M. (2004). Bringing engineering to elementary school. Journal of STEM Education. Innovations and Research, 5(3/4), 17.

Somyurek, S. (2015). An effective educational tool: Construction kits for fun and meaningful learning. International Journal of Technology and Design Education, 25, 25-41.

Sullivan, A., Bers, M.U. (2013). Gender differences in kindergarteners' robotics and programming achievement. International Journal of Technology and Design Education, 23(3), 691-702.

Ucgul, M. (2013). History and educational potential of Lego mindstorms NXT. Mersin University Journal of the Faculty of Education, 9(2), 127-137.

Yin, R. K. (2009). Doing case study research. 4th ed. Thousand Oaks, CA: Sage.

S. Kucuk (Dr.) works at the Department of Computer Education \& Instructional Technology at Istanbul University-Cerrahpasa, Turkey. Her research interests are in the educational robotics, augmented reality technology, mobile learning, technology integration, teacher education, online education, instructional design, instructional strategies, and research methods.

B. Sisman is currently working as Assistant Professor in the Department of Computer Education \& Instructional Technology at Istanbul University-Cerrahpasa, Turkey. His research interests are in the educational robotics, signal processing, technology integration, online learning, teacher education, augmented and virtual reality, 3D virtual environments. 